This is the final peer-reviewed accepted manuscript of

Mazzei L.; Ciurli S.; Cravotto G.; Grillo G.; Guidi E.; Pasteris A.; Tabasso S.; Samori C.; Galletti P.: Urease Inhibitory Potential and Soil Ecotoxicity of Novel "polyphenols-Deep Eutectic Solvents" Formulations. ACS SUSTAINABLE CHEMISTRY \& ENGINEERING, 7. ISSN 2168-0485

DOI: 10.1021/acssuschemeng.9b03493

The final published version is available online at:

http://dx.doi.org/10.1021/acssuschemeng.9b03493

Rights / License:

The terms and conditions for the reuse of this version of the manuscript are specified in the publishing policy. For all terms of use and more information see the publisher's website.

This item was downloaded from IRIS Università di Bologna (https://cris.unibo.it/)

When citing, please refer to the published version. 


\title{
Urease Inhibitory Potential and Soil Ecotoxicity of Novel "Polyphenols-Deep Eutectic Solvents" Formulations
}

\author{
Chiara Samorì, ${ }^{* \dagger}{ }^{\dagger}$ Luca Mazzei, ${ }^{\ddagger}$ Stefano Ciurli, ${ }^{\ddagger}$ Giancarlo Cravotto, " Giorgio Grillo," \\ Elena Guidi, ${ }^{\S}$ Andrea Pasteris, ${ }^{\S}$ Silvia Tabasso, ${ }^{\prime \prime}$ and Paola Galletti ${ }^{\dagger}$ \\ †Department of Chemistry “Giacomo Ciamician” and ${ }^{\S}$ Department of Biological, Geological and Environmental Sciences \\ (BiGeA), University of Bologna, Via S. Alberto 163, Ravenna, Italy \\ Department of Pharmacy and Biotechnology, University of Bologna, Viale Fanin 40, Bologna, Italy \\ "Dipartimento di Scienza e Tecnologia del Farmaco, University of Turin, Via P. Giuria 9, Turin, Italy
}

\begin{abstract}
New formulations based on red grape pomace polyphenols and deep eutectic solvents (DES) have been here evaluated as inhibitors of urease of agricultural interest (jack bean urease, JBU). DES based on choline chloride ( $\mathrm{CHO}$ ) and betaine (BET), combined with ethylene glycol (EG), citric acid (CA), and urea $(\mathrm{U})$, were used both as extracting and carrying agents for polyphenols, becoming active components of the formulations here obtained. Among the various DES combinations, $U$ and CA based ones gave the best polyphenol extraction performances, 1.2-1.4 times higher than those of the hydroalcoholic mixture. Among the various DES-polyphenols formulations, the one composed by $\mathrm{CHO}-\mathrm{EG}$ showed the best antioxidant potential

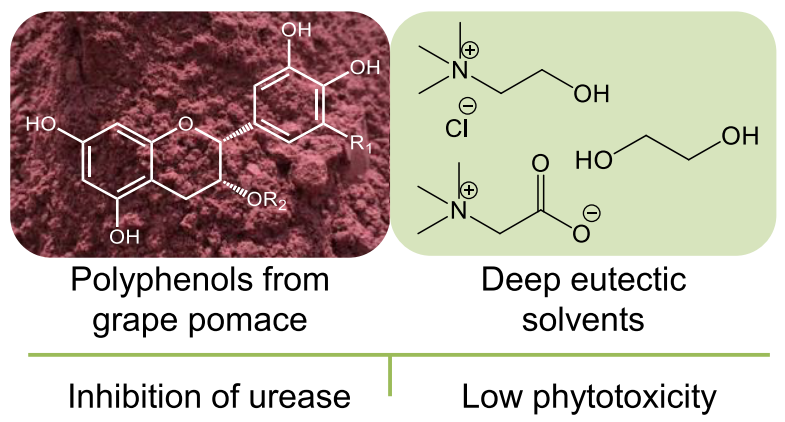
and urease inhibition: 60-90\% inhibition of the total JBU activity was achieved with a CHO concentration of 5-20 mM. Good results were also achieved with the BET-EG polyphenol formulation, which was able to inhibit ca. $50 \%$ of urease activity at 20 $\mathrm{mM}$ concentration of BET. Low phytotoxicity of DES and their polyphenol formulations tested at a concentration of $34 \mathrm{mM}$ of $\mathrm{CHO}$ or BET was here observed on cress seedlings and the early growth of oat, in particular, for EG based DES. On the other hand, tests performed on earthworms showed that CHO based DES could impair the reproduction, and U based DES caused severe mortality.
\end{abstract}

KEYWORDS: Deep eutectic solvents, Polyphenols, Antiurease activity, Grape byproducts, Antioxidant potential, Phytotoxicity, Earthworms

\section{INTRODUCTION}

Urease is a $\mathrm{Ni}(\mathrm{II})$ dependent enzyme widely spread in nature and produced by plants, fungi, and bacteria. ${ }^{1-4}$ It is of critical importance in the global nitrogen cycle by hydrolyzing urea to eventually yield $\mathrm{NH}_{3}$ and $\mathrm{CO}_{2},{ }^{5,6}$ a reaction that causes an overall increase of soil $\mathrm{pH} .{ }^{1,2,4,7}$ Soils contain large quantities of urease, both inside living cells of plants and microbes, and as an extracellular enzyme adsorbed onto organic and inorganic soil components and protected from decomposition. ${ }^{1}$ Urea is the main source of $\mathrm{N}$ in worldwide crop production thanks to several commercial and safety advantages if compared to other $\mathrm{N}$ fertilizers such as ammonium nitrate. However, its rapid hydrolytic decomposition catalyzed by soil urease results in a substantial decrease in the efficiency of urea based soil fertilization due to a fast ammonia volatilization process that leads to a loss of $\mathrm{N}$ to the atmosphere (it has been estimated that about $40 \%$ of $\mathrm{N}$ in urea fertilizers can be lost within days of application). ${ }^{8}$ Moreover, the rapid $\mathrm{pH}$ increase associated with urea decomposition negatively impacts plant germination or early growth, further decreasing the amount of ammonium absorption by plant roots. Ammonia volatilization also has impacts on both local and international (transboundary) scales, contributing to atmospheric pollution with the production of $\mathrm{NH}_{4}^{+}$containing secondary aerosol (the major fraction of PM2.5 aerosols) in the atmosphere by reacting with acid pollutants (e.g., $\left.\mathrm{SO}_{2}, \mathrm{NOx}\right) .{ }^{9}$ The practice of using urease inhibitors as $\mathrm{N}$ stabilizers has been implemented to counter balance these negative aspects in various ecosystems. ${ }^{10}$ The most widely used urease inhibitor for agronomic purposes is $N$ ( $n$ butyl) thiophosphoric triamide (NBPT), which belongs to the class of those inhibitors that directly bind to the $\mathrm{Ni}$ (II) ions in the active site of the enzyme. ${ }^{3,4}$ Despite its effectiveness, characterized both in vitro and in vivo, ${ }^{1,12}$ and the determination of the mechanism of inhibition at a molecular level, $^{13}$ NBPT does not meet some of the essential characteristics necessary for agronomic applications, especially 
in terms of low phytotoxicity, since it causes leaf necrosis in several crop plants. ${ }^{14-16}$ A second group of inhibitors, to which catechol (1,2 dihydroxybenzene) belongs, ${ }^{17}$ is able to cova lently bind to a conserved cysteine residue located on a protein flap (involved in the catalytic mechanism by modulating substrate) product exchange across the active site cavity), blocking the enzyme activity. In particular, the mechanism of urease inactivation by catechol has been suggested to be radical promoted, with a mode of action hypothesized to be a common denominator for aromatic polyhydroxylated urease inhibitors like polyphenols. ${ }^{17}$

Polyphenols are bioactive plant metabolites, potentially exploitable in a broad range of human related applications. Among the variety of useful biological properties (e.g., anticancer, anti inflammatory, antibacterial, cardioprotective, antiosteoporotic properties), polyphenols also exhibit en zyme -inhibitory activities, like against the enzyme urease itself. ${ }^{3}$ For example, ethanolic extracts enriched in polyphenols obtained from perennial and deciduous trees (e.g., from the bark of Acacia decurrens, Acacia caven, and Pinus radiate, or from the seed coat of Terminalia chebula) as well as whole plants (e.g., Camellia sinensis $\underset{18-20}{\text { and }}$ Azadirachta indica) were effective against soil ureases. $^{18-20}$

The aim of the present study was to develop safe and cheap formulations, useful in agricultural applications, by exploiting the proven inhibition potential of polyphenols against urease. The antiurease formulations herein developed were based on polyphenols extracted from red grape pomace with deep eutectic solvents (DES), demonstrating a novel approach for the valorization of winery byproducts aiming to reduce the fast ammonia volatilization after soil fertilization with urea based fertilizers. The use of DES for extracting polyphenols from a variety of natural matrixes has been widely explored, exploiting the possibility of tuning the extraction ability by combining specific hydrogen bond acceptors (HBA) (e.g., choline chloride) and hydrogen bond donors (HBD) (e.g., amides, amines, alcohols, and carboxylic acids). ${ }^{21}$ However, their use as both extracting agents and polyphenols carriers, incorporating DES into bioactive formulations, is a relatively new concept that (i) exploits DES peculiarities (e.g., tunable extraction power, nonvolatility, and biocompatibility); (ii) can improve the bioavailability, diffusion, and transport of bioactive ingredients with a limited solubility in conventional solvents; $^{22-24}$ (iii) can open the possibility of using novel DES based materials; (iv) can increase the overall sustain ability of the process bypassing the need for downstream purification steps aimed at DES removal with consequent solvent consumption. This unusual DES exploitation as "ingredients" requires an ad hoc investigation of their bio logical properties, targeted for the specific application (e.g., cosmetics, pharmaceutical or agricultural formulations, or food manufacturing). Although the low harmfulness/toxicity of many single DES components is well established, the (eco) toxicological profile of DES is not so detailed; ${ }^{25}$ moreover, it is still not clear if there could be a synergistic effect between DES ingredients that would result in a greater toxicity of the mixture than the toxicity of each single component. $^{26}$ To this purpose, the toxicity of DES and their polyphenol formulations was assessed against biological targets that could be affected by DES used for agricultural applications: plants (at different growth stages) and earthworms.

To the best of our knowledge, this is the first time that
- polyphenols extracted from grape pomace (and wine byproducts in general) have been tested as plant derived natural inhibitors of urease;

- DES have been used as polyphenol "extracting agents" and "carriers" for agricultural applications;

- DES have been used for preparing formulations with antiurease activity;

- biological effects of DES (and their polyphenol formulations) have been investigated on plant emergence and early growth, and on earthworm survival and reproduction.

\section{EXPERIMENTAL SECTION}

Chemicals. All chemicals and solvents were purchased from Sigma Aldrich and used without any further purification. Jack bean urease (Canavalia ensiformis, JBU) Type C 3 , powder, $\geq 600$ units $\mathrm{mg}$ ${ }^{-1}$ solid, was used for the experiments.

Red Grape Pomace. Red grape pomace from red grape (Vitis vinifera L.) varieties were collected during September 2015 in the Emilia Romagna region (Italy) and obtained by processing "Sangiovese" red vines by Caviro Extra s.p.a. (Faenza, Italy); after the collection, it was immediately freeze dried, ground with a domestic miller, and stocked at $4{ }^{\circ} \mathrm{C}$ until the preparation of DES formulations (May 2018).

DES Preparation. DES (betaine-citric acid, BET-CA; betaineethylene glycol, BET-EG; betaine-urea, BET-U; choline chloridecitric acid, $\mathrm{CHO}-\mathrm{CA}$; choline chloride-ethylene glycol, $\mathrm{CHO}-\mathrm{EG}$; choline chloride-urea, $\mathrm{CHO}-\mathrm{U}$ ) were prepared by mixing appropriate stoichiometric ratios of two hydrogen bond acceptors (HBA, choline chloride $\mathrm{CHO}$, and betaine BET) and three different hydrogen bond donors (HBD) at the appropriate HBA:HBD molar ratio: citric acid (CIT, 1:1), ethylene glycol (EG, 1:2), and urea (U, 1:2). The mixtures were heated at $70^{\circ} \mathrm{C}$ and magnetically stirred until uniform colorless liquids were obtained; then distilled water (40 wt\%) was added to get a homogeneous liquid phase.

Red Grape Pomace Extraction. Each DES ( $2 \mathrm{~g}$ ) was added to freeze dried red grape pomace $(50 \mathrm{mg})$, and the mixture was stirred at rt for $24 \mathrm{~h}$. Extractions with $\mathrm{H}_{2} \mathrm{O}, \mathrm{EtOH}$, and $\mathrm{H}_{2} \mathrm{O} / \mathrm{EtOH} 1: 1$ (v/v)(2 g) were performed for comparison. After $24 \mathrm{~h}$, each mixture was centrifuged and separated from residual biomass; the extracts were analyzed in terms of polyphenol and sugar content, and antioxidant potential. Each extraction was performed in triplicate. Extracts containing DES and polyphenols were named "DES-PF formulations" hereafter. The polyphenol content in the extracts was quantitatively determined through the Folin Ciocalteau protocol (see Supporting Information) and expressed as a percentage on biomass (red grape pomace) dry weight basis (wt \%). The amount of polyphenols in each formulation was checked periodically every 30 days through the Folin Ciocalteau protocol to determine their stability over the time. The qualitative phenolic profile in terms of groups of compounds of $\mathrm{CHO}-\mathrm{EG}-\mathrm{PF}$ formulation and EtOH extract was determined by high performance liquid chromatography (HPLC) (see Supporting Information).

The antioxidant activity of the extracts was determined by using 2,2 diphenyl 1 picrylhydrazyl (DPPH•) radical (see Supporting Information); the concentration that inhibits $50 \%$ of DPPH• production $\left(\mathrm{IC}_{50}\right)$ was graphically calculated through a calibration curve in the linear range (extract concentration vs scavenging effect). Trolox equivalents (TE) $\mu \mathrm{g} \mathrm{mL}^{-1}$ of extract were calculated according to the $\mathrm{IC}_{50}$.

Urease Inhibition Assay. The activity of Canavalia ensiformis (jack bean) urease (JBU) in the absence and in the presence of DES and DES-PF formulations was determined by using the $\mathrm{pH}$ STAT method $^{27}$ in $2 \mathrm{mM}$ HEPES buffer at $\mathrm{pH} 7.5$, also containing $2 \mathrm{mM}$ EDTA to remove any possible metal contamination that could inhibit urease (reaction buffer, RB). A T1 $\mathrm{pH}$ meter equipped with a 50-14 T electrode (Crison Instruments) was used to record the volume of a $100 \mathrm{mM} \mathrm{HCl}$ solution necessary to maintain the reaction mixture 
(total volume of $10 \mathrm{~mL}$ ) at the fixed $\mathrm{pH}$ value of 7.5 for a $3 \mathrm{~min}$ reaction time conducted under constant stirring at rt. Urease activity was measured in accordance with the amount of $\mathrm{HCl}$ used for $\mathrm{pH}$ neutralization, defining one unit of enzyme as the amount of urease required to hydrolyze $1 \mu \mathrm{mol}$ urea $\mathrm{min}^{-1}$ of reaction. Three DES and DES-PF concentrations were used: 5,10 , and $20 \mathrm{mM}$, referred to the final concentration of HBA (BET or $\mathrm{CHO}$ ) in the reaction mixture. According to the tested DES, the reaction mixtures were composed as follows:

- BET-EG, CHO-EG, and their PF formulations: $9.75 \mathrm{~mL}$ of $\mathrm{RB}, \mathrm{DES}$ or DES-PF formulations and $0.1 \mathrm{~mL}$ of $100 \mathrm{nM}$ JBU. The reaction was initiated upon the addition of $0.12 \mathrm{~mL}$ of $8 \mathrm{M}$ urea to the reaction mixture, reaching $100 \mathrm{mM}$ as a working substrate concentration.

- BET-CA, CHO-CA, and their PF formulations: since the $\mathrm{pH}$ of $\mathrm{RB}$ decreased after the addition of CA based DES, the $\mathrm{pH}$ of the reaction mixtures was restored at the initial value by adding concentrated $\mathrm{NaOH}$; then $0.1 \mathrm{~mL}$ of $100 \mathrm{nM} \mathrm{JBU}$ was added, and the reaction was initiated as previously described.

- BET-U, CHO-U, and their PF formulations: since substrate urea was provided by DES themselves, the reaction mixtures were composed by $9.90 \mathrm{~mL}$ of $\mathrm{RB}$ and DES or DES-PF formulations; the reaction was initiated upon the addition of $0.1 \mathrm{~mL}$ of $100 \mathrm{nM} \mathrm{JBU}$. No further urea was provided as a substrate source.

All the measurements started $0.5 \mathrm{~min}$ after urea (or JBU) addition to reach a uniform substrate/enzyme concentration in the reaction mixture. The enzyme activity values measured in each experimental condition, recorded as triplicates and averaged, were normalized with respect to the urease activity measured in the absence of any DES (reference experiment) and plotted, as a percentage, as a function of the amount of DES-PF formulation tested.

DES Concentration for Ecotoxicity Tests. A single concentration of DES and DES-PF formulations $(60 \mathrm{mM})$ was tested in all the toxicity tests: this corresponded to a final concentration of $34 \mathrm{mM}$ for the two HBA (BET of CHO), of $34 \mathrm{mM}$ for citric acid, and $68 \mathrm{mM}$ for ethylene glycol and urea. This concentration was chosen based on DES concentration tested in the literature in germination and phytotoxicity assays $(0.5-100 \mathrm{mM}){ }^{28,29}$

Filter Paper Contact Germination Test. Germination tests on seeds of cress (Lepidium sativum L.) were conducted according to the procedure described in UNI 11357:2010 (see Supporting Information)..$^{30}$ Seed germination data were reported after $72 \mathrm{~h}$ as relative seed germination percentage (RSG, \%) with respect to the control (distilled water). Shoot length and root length data were reported as relative shoot length percentage (RSL, \%) and relative root length percentage (RRL, \%) with respect to the control (distilled water).

Plant Emergence and Early Growth Test. The effects of DES, single DES components, and DES-PF formulations on the emergence and early growth of higher plants (oat, Avena sativa L. and cress, L. sativum) were tested according to ISO 11269 2:2012. ${ }^{31}$ Shoot length, biomass (mass of the five shoots in each pot after drying at $60^{\circ}$ $\mathrm{C}$ for $48 \mathrm{~h}$ ), and visible damages (chlorosis, necrosis, wilting, deformations) were evaluated as end points at the end of the test.

Earthworm Reproduction Test. The earthworm Eisenia andrei Bouchè, 1972 was used to run a 56 days reproductive toxicity test according to the OECD Guideline No. 222 (see Supporting Information). ${ }^{32}$ The effects on reproduction at the end of the experiment were assessed by determining the number and weight of juvenile earthworms and the number of both hatched and unhatched cocoons at the end of the test.

\section{RESULTS AND DISCUSSION}

Red Grape Pomace Extraction with DES. Grape byproducts (e.g., grape pomace, grape seeds, grape skin, and lees) are highly appealing in terms of antioxidant potential due to their high polyphenol content. The extraction of these polyphenols with DES and natural DES (NaDES) has been previously performed by testing various $\mathrm{HBA}-\mathrm{HBD}$ combi nations, eventually assisted by microwave and ultra sounds: $:^{23,33-38}$ HBA like $\mathrm{CHO}$ or BET coupled with various organic acids, sugars, and sugar derivatives were investigated. ${ }^{23,33,34,36,37,39}$ Three parameters were found to play a crucial role in determining extraction efficiency: water content (that reduces DES viscosity and increases DES polarity), ${ }^{34}$ acidity (that influences the equilibrium forms and stability of some specific polyphenols), ${ }^{33,34}$ and polarity of DES. For example, the extraction of anthocyanins (polar polyphenols) is more effective with acidic DES than through neutral ones (sugars or polyols based DES), thanks to the combination of higher polarity and lower $\mathrm{pH}$.

The results achieved here with DES composed by choline chloride and betaine as HBAs, and citric acid, ethylene glycol, and urea as HBDs, indicated that the performance of various DES were significantly different and dependent by HBD-HBA combinations (Figure 1).

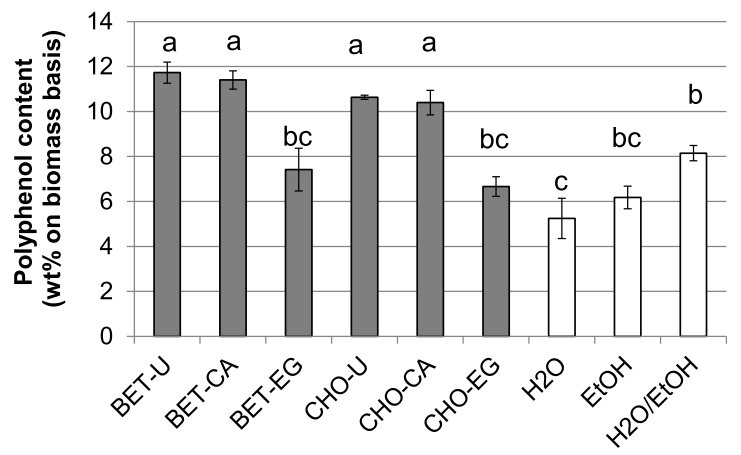

Figure 1. Total polyphenol extraction yields (wt \%, on biomass dry weight basis) with different DES, $\mathrm{H}_{2} \mathrm{O}, \mathrm{EtOH}$, and $\mathrm{H}_{2} \mathrm{O} / \mathrm{EtOH}$ 1:1 $(\mathrm{v} / \mathrm{v})$. Values are reported as mean \pm standard error $(n=3)$. Treatments marked with the same letter are not significantly different from each other.

EG based DES, in combination with both BET and $\mathrm{CHO}$, behaved similarly and was significantly less efficient than all other DES tested $(p<0.01)$, in line with literature data; BETEG and CHO-EG were also not statistically different from conventional solvents $\left(\mathrm{H}_{2} \mathrm{O}, \mathrm{EtOH}\right.$, and $\left.\mathrm{H}_{2} \mathrm{O} / \mathrm{EtOH} 1 / 1\right)$. Citric acid or urea, coupled with BET and $\mathrm{CHO}$, gave similar polyphenol content, significantly higher than the mixture $\mathrm{H}_{2} \mathrm{O}$ / EtOH $1 / 1(p<0.05)$. All DES extracts also contained a significant portion (64-100\%, Table S1, supporting Information) of the total sugars present in red grape pomace $(22 \pm 4 \mathrm{wt}$ $\%)$, as a direct consequence of their polar nature and high affinity for polar metabolites. ${ }^{40,41}$

Urease Inhibition Assay. The inhibition properties of DES -PF formulations on JBU were evaluated as enzymatic residual percentage activity in the absence and in the presence of DES -PF formulations (tested at HBA concentration of 5, 10, and $20 \mathrm{mM}$, Figure 2). Urease activity was not affected when incubated in urea based DES-PF (BET-U-PF and CHO-U $-\mathrm{PF}$ ) (Figure 2, panels $\mathrm{a}$ and $\mathrm{b}$, respectively) in the concentration range used. Citric acid based DES, BET-CA$\mathrm{PF}$ and $\mathrm{CHO}-\mathrm{CA}-\mathrm{PF}$ (Figure 2, panels $\mathrm{c}$ and d, respectively) had a moderate inhibitory action against JBU; in particular, $\mathrm{BET}-\mathrm{CA}-\mathrm{PF}$ was statistically different from the control at each tested concentration. Both BET-CA-PF and $\mathrm{CHO}-\mathrm{CA}$ $-\mathrm{PF}$, tested at $5 \mathrm{mM}$ HBA concentration, reduced the original enzyme activity by ca. $10-20 \%$, with an inhibition 

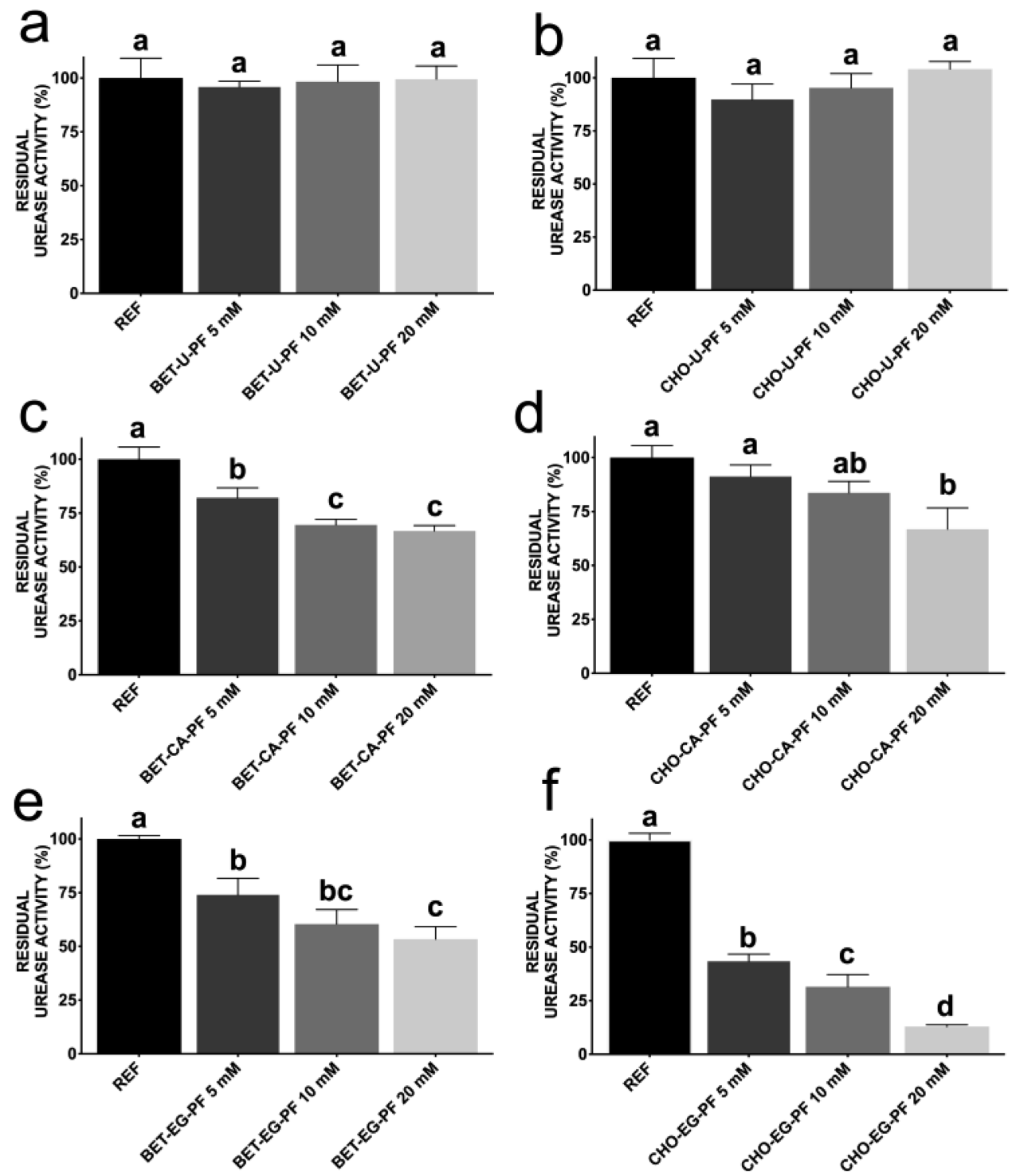

Figure 2. Residual percentage activity of urease, referenced to $100 \%$ (control, black bar) in the presence of increasing concentrations of (a) BET$\mathrm{U}-\mathrm{PF}$, (b) CHO-U-PF, (c) BET-CA-PF, (d) CHO-CA-PF, (e) BET-EG-PF, and (f) CHO-EG-PF. The dark gray, gray, and light gray bars correspond to 5,10 , and $20 \mathrm{mM}$ of HBA tested, respectively.

strength that increased to ca. $30-40 \%$ at the highest HBA concentration used $(20 \mathrm{mM})$. A slight activity increase in the case of CA based formulations was observed, ascribable to the presence of citric acid, as previously reported. ${ }^{42}$ The strongest inhibition profile resulted by incubating JBU with BET-EG$\mathrm{PF}$ and $\mathrm{CHO}-\mathrm{EG}-\mathrm{PF}$ (Figure $2 \mathrm{e}-\mathrm{f}$ ).

$\mathrm{CHO}-\mathrm{EG}-\mathrm{PF}$ tested at an HBA concentration of $5 \mathrm{mM}$ inhibited ca. $60 \%$ of the total JBU activity, whereas the inhibition increased up to ca. $90 \%$ when a four times higher HBA concentration $(20 \mathrm{mM})$ was tested. On the other hand, a urease activity reduction of ca. $50 \%$ was observed by using BET $-\mathrm{EG}-\mathrm{PF}$ at $20 \mathrm{mM} \mathrm{HBA}$ concentration. Control experiments performed incubating JBU with DES showed that the activity of the enzyme was not affected by DES alone (Figure S1, Supporting Information), confirming the role of specific polyphenols extracted by $\mathrm{CHO}-\mathrm{EG}$ and $\mathrm{BET}-\mathrm{EG}$ from red grape pomace as urease inhibitors. To the best of our knowledge, this is one of the few examples of natural plant derived extracts that have been investigated as urease inhibitors of agricultural interest, and the first report on the use of wine industry byproducts for such applications; thus, these results can open novel possibilities of valorization for the high added value content of these residues, in a field never explored before. Antioxidant Activity and Phenolic Profiles. The evaluation of the antioxidant activity of DES-PF formulations and EtOH extract assessed through the scavenging of $\mathrm{DPPH} \bullet($ Table 1) did not indicate a well defined correlation with polyphenol extraction performance (Figure 1). Among the BET formulations, BET-U-PF had the highest antioxidant activity and BET-CA-PF had the lowest one, even if these two DES had similar polyphenol extraction performances (Figure 1). Among the $\mathrm{CHO}$ formulations, $\mathrm{CHO}-\mathrm{EG}-\mathrm{PF}$ (the extract with the lowest amount of polyphenols) had the highest antioxidant activity, whereas $\mathrm{CHO}-\mathrm{U}-\mathrm{PF}$ (that extracted polyphenols similarly to BET-U-PF, BET-CA- PF, and $\mathrm{CHO}-\mathrm{CA}-\mathrm{PF}$ ) the lowest one. The extraction efficiency, evaluated by the Trolox equivalents $\left(\mu \mathrm{g} \mathrm{mg}_{\text {Matrix }}{ }^{-1}\right.$, Table 1$)$ confirmed the activity of CHO-EG-PF, as well as the poor effect of CHO-U-PF. For sake of comparison, EtOH extract (not statistically different from $\mathrm{CHO}-\mathrm{EG}-\mathrm{PF}$ 
Table 1. Antioxidant Activity of DES-PF Formulations ${ }^{a}$

$\begin{array}{cccc}\text { extracts } & \mathrm{IC}_{50}\left(\mathrm{mg} \mathrm{mL}^{-1}\right) & \mathrm{TE}\left(\mu \mathrm{g} \mathrm{mL}^{-1}\right) & \mathrm{TE}\left(\mu \mathrm{g} \mathrm{mg}_{\text {Matrix }}{ }^{-1}\right) \\ \text { BET U PF } & 0.88 & 0.15 & 1.6800 \\ \text { BET CA PF } & 3.74 & 0.050 & 0.1911 \\ \text { BET EG PF } & 1.50 & 0.15 & 1.6766 \\ \text { CHO U PF } & 13.76 & 0.023 & 0.0400 \\ \text { CHO CA PF } & 3.46 & 0.069 & 0.3608 \\ \text { CHO EG PF } & 0.56 & 0.17 & 2.3039 \\ \text { EtOH } & 1.55 & 0.15 & 1.6583\end{array}$

${ }^{a} \mathrm{IC}_{50}$ values are expressed as $\mathrm{mg}$ of sample per $\mathrm{mL}$ solution; Trolox equivalent values (TE) are expressed as $\mu \mathrm{g} \mathrm{mL}^{-1}$ of analysis formulation, according to $\mathrm{IC}_{50}$, and $\mu \mathrm{g} \mathrm{mg}_{\text {Matrix }}{ }^{-1}$, normalized on extracted biomass.

in terms of polyphenols content, Figure 1) was chosen for the $\mathrm{DPPH} \bullet$ assay, displaying an antioxidant activity close to that of BET-EG-PF and BET-U-PF. DES alone showed no antioxidant activity (data not reported), and therefore the apparent discrepancy between the total PF determination and $\mathrm{DPPH} \bullet$ assay could be ascribed to possible polar "interfering compounds" (as reducing sugars or proteins) extracted by DES, that could partially affect the total polyphenol Folinspectrophotometric quantitation.

Since CHO-EG-PF was the formulation that had the highest antioxidant activity and the highest inhibition effect on urease compared to the other DES, it was further characterized by HPLC to determine its composition in terms of classes of polyphenols, identified on the basis of their UV-vis spectral fingerprints, and by comparison with the literature (Table S2, Supporting Information). The EtOH extract was also characterized for sake of comparison (representative chromatograms of both extracts are shown in Figures S2-4, Supporting
Information). Indeed, even if nonstatistically different in terms of polyphenol content from CHO-EG-PF (Figure 1), EtOH extract displayed a lower antioxidant activity (as reported in Table 1); therefore, the composition analysis could be helpful in explaining this behavior. Grape pomace is characterized by a high phenolic content (not extractable during the winemaking process and influenced by the cultivar and vintage), with a complex profile that includes flavonol glycosides, phenolic acids and alcohols, catechins, stilbenes, hydroxycinnamic acids, proanthocyanidines, and anthocyanins. ${ }^{43,44}$ Phenolic acids and anthocyanins seemed more abundant in $\mathrm{EtOH}$ extract, whereas CHO-EG-PF formulation appeared enriched in a variety of catechins and gallic acid (the latter not found in $\mathrm{EtOH}$ extract). Specifically, different compounds referable to proanthocyanidines were detected in the range of 19.5-22.2 min in EtOH extract (Figure S2a, Supporting Information). The broad peak between 16 and $26 \mathrm{~min}$ in CHO-EG-PF formulation can be due also to the presence of this kind of products (Figure S2b, Supporting Information). The inhibitory effect on $H$. pylori ureases of gallic acid derivatives, flavanols (e.g., catechin and catechin derivatives), flavonols (e.g., quercetin), and flavones (e.g., baicalin) is well documented. ${ }^{20}$ All of these polyphenols are characterized by a "catechol like" structure, known to cause an urease irreversible inactivation through the formation of a covalent adduct with a conserved cysteine residue on the active site channel of the enzyme, blocking it in the open position. ${ }^{17}$ Therefore, the conspicuous presence of catechins, condensed catechins (proanthocyani dins), anthocyanins, and gallic acid in CHO-EG-PF formulation could explain its strong antiurease activity here discovered. a)

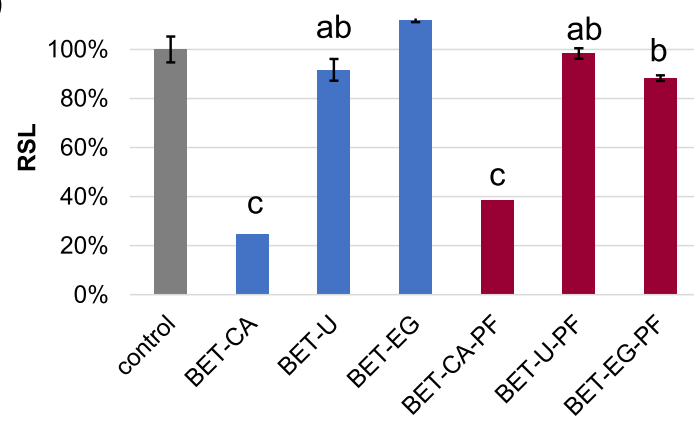

c)

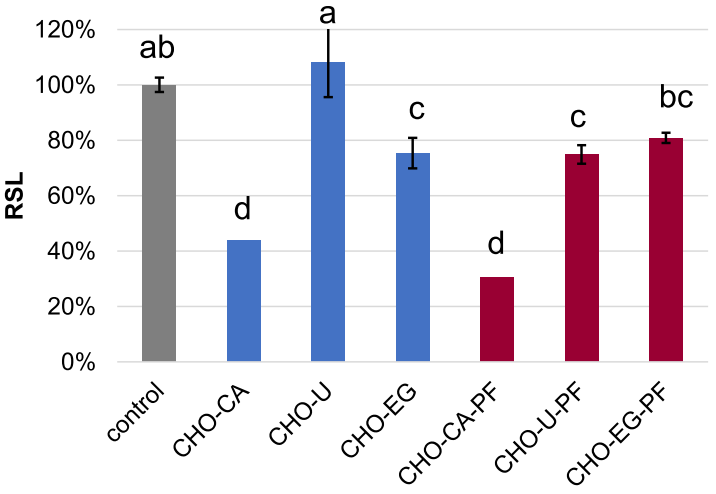

b)

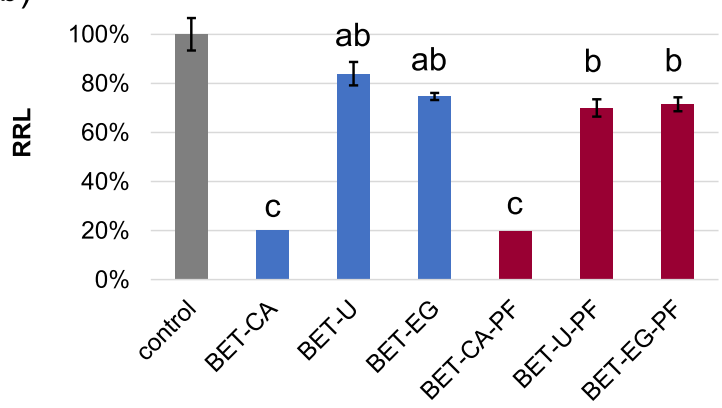

d)

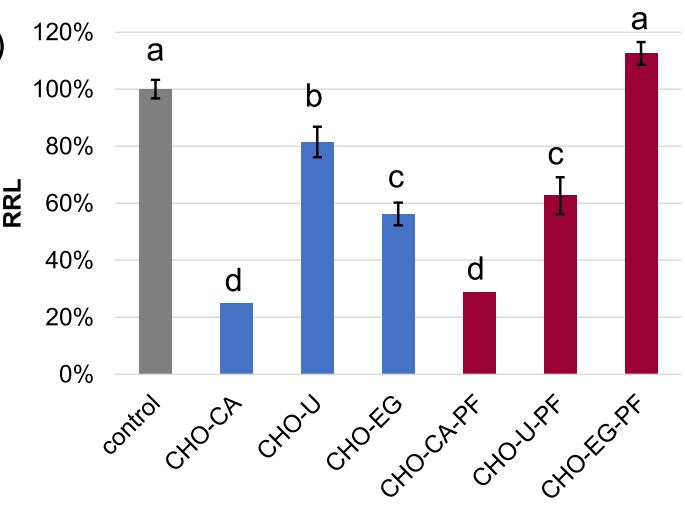

Figure 3. Effect of different DES and DES-PF formulations on Lepidium sativum germination in a filter paper contact test. Relative shoot length percentage (RSL, \%): (a) BET series; (c) CHO series. Relative root length percentage (RRL, \%): (b) BET series; (d) CHO series. Values are reported as mean \pm standard error $(n=4)$. Treatments marked with the same letter are not significantly different from each other. 

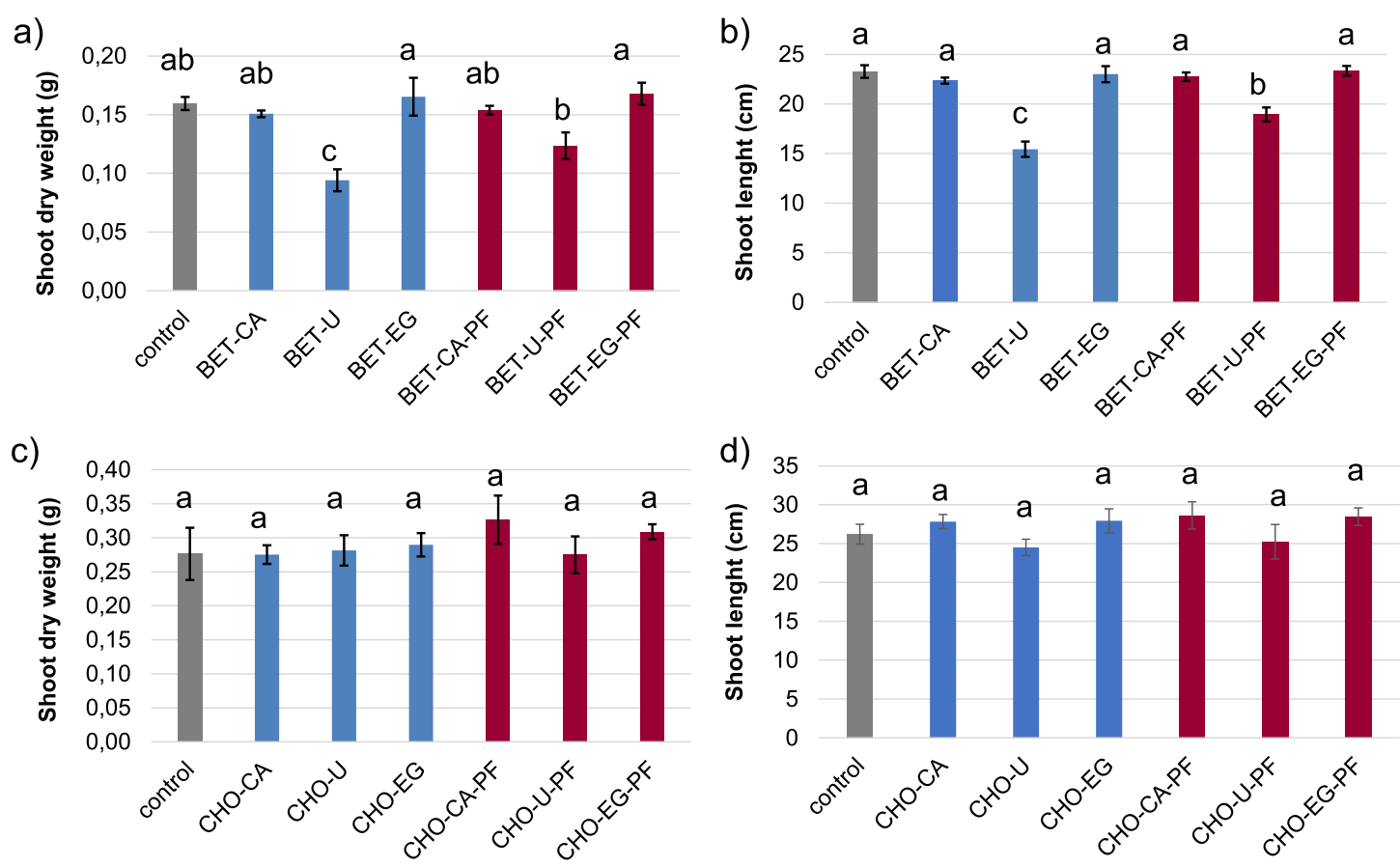

Figure 4. Effect of different DES and DES-PF formulations applied into the soil on early growth of Avena sativa. Shoot weight (g): (a) BET series; (c) $\mathrm{CHO}$ series. Shoot length (cm): (b) BET series; (d) CHO series. Values are reported as mean \pm standard error $(n=4)$. Treatments marked with the same letter are not significantly different from each other.

Germination Test. The impact on cress (Lepidium sativum) seed germination was determined by testing the effect of the six DES and the corresponding DES-PF formulations (Figure 3 ) at the same concentration ( $34 \mathrm{mM}$ of HBA). This kind of evaluation has been previously reported on Allium sativum (garlic) cloves and Triticum aestivum (wheat) seeds, determining the effects of $\mathrm{CHO}$ based DES with various $\mathrm{HBD}$ (oxalic acid, urea, acetamide, glycerol, ethylene glycol and glucose) ${ }^{28}$ To the best of our knowledge, BET based DES have never been evaluated before.

Neither DES nor their formulations influenced seed germination: the relative seed germination percentages (RSG, $\%$ ) calculated for each compound were $100 \%$ in all cases. On the other hand, both relative shoot length percentage (RSL, \%) and relative root length percentage (RRL, \%) were affected by DES and DES-PF, reflecting specific combinations of HBD and HBA as confirmed by the literature. ${ }^{45}$ This is in line with that found for the germination of wheat seeds: early growth of seedlings is more sensitive than seed germination. ${ }^{28}$ However, differently from what occurred with wheat seeds, root growth inhibition was not clearly more pronounced than the shoot one. CA strongly inhibited both shoot and root growth, regardless of the HBA and presence of polyphenols; RSL and RRL were significantly lower than control $(p<0.001)$, around $20-40 \%$ of the shoot and root growth of the control. No clear trend was observed for the other two HBD:

- RSH and RRL of seeds treated with BET-U were not significantly different from the control, whereas the treatment with its polyphenol formulation (BET-UPF) inhibited root length $(p<0.05)$. Similarly, the shoot length of seeds treated with $\mathrm{CHO}-\mathrm{U}$ was not significantly different from the control, while the root length was $(p<0.01)$. On the other hand, the inhibition caused by $\mathrm{CHO}-\mathrm{U}-\mathrm{PF}$ formulation was highly significant on both RSL $(p<0.01)$ and RRL $(p<0.001)$.
- RSL and RRL of seeds treated with BET-EG were not significantly different from the control, whereas the treatment with its polyphenol formulation (BET-EGPF) inhibited root length $(p<0.05)$. An opposite trend was found with CHO-EG: DES alone significantly inhibited both shoot and root growth $(p<0.01)$, whereas the seeds treated with its polyphenol formulation (CHO-EG-PF) were not significantly different from the control both in terms of RSL and RRL.

The comparison among betaine based DES showed that BET $-\mathrm{U}$ and BET-EG did not significantly affect seedling growth, whereas BET-CA had a strong inhibitory effect. Within the choline based series, the following trend of HBD toxicity was found: citric acid > ethylene glycol > urea. Analogously, the literature reports a more pronounced inhibition of garlic cloves root growth with CHO-EG than CHO $-\mathrm{U}$, and a more pronounced inhibition of wheat seeds root growth with acidic DES (CHO-oxalic acid) than neutral ones (CHO-glycerol or $\mathrm{CHO}-$ glucose) reasonably explained by a lower $\mathrm{pH}$ of the formers. In the present study, the $\mathrm{pH}$ of the DES solutions in which cress seeds were placed was $2.5-2.3$ for acidic DES (BET-CA and CHO-CA, respectively) and 6.0-5.8 for neutral ones (BET-EG and CHO-EG, respectively); the effects of the single components of those DES that were markedly more toxic than the control (CHO- CA, CHO-EG, BET-CA and BET-EG) have been reported in Supporting Information (Figure S5). Noticeably, both CHO-EG-PF and BET-EG-PF formulations, tested at a HBA concentration $(34 \mathrm{mM})$ that was 1.7 times higher than the dose able to inhibit 90 and $50 \%$ of urease activity $(20 \mathrm{mM})$, respectively, did not negatively affect both seed and root elongation.

Plant Emergence and Early Growth Test. The effect on seedling emergence and early growth of higher plants following 
a)

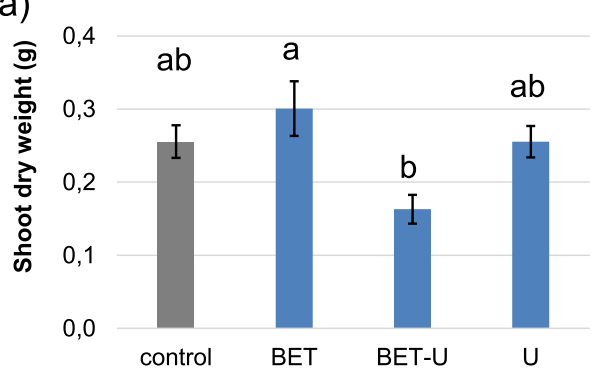

b)

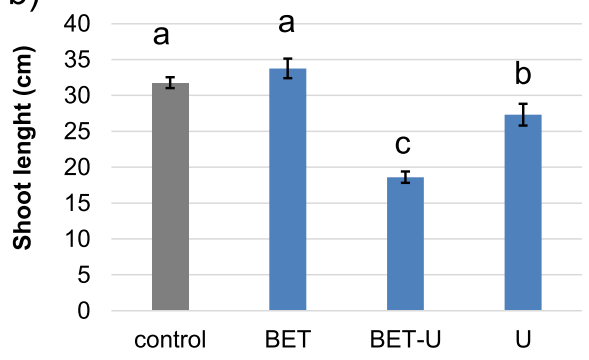

Figure 5. Effect of BET-U, BET, and U applied into the soil on early growth of A. sativa, expressed as (a) shoot weight (g); (b) length (cm). Values are reported as mean \pm standard error $(n=4)$. Treatments marked with the same letter are not significantly different from each other.

a)
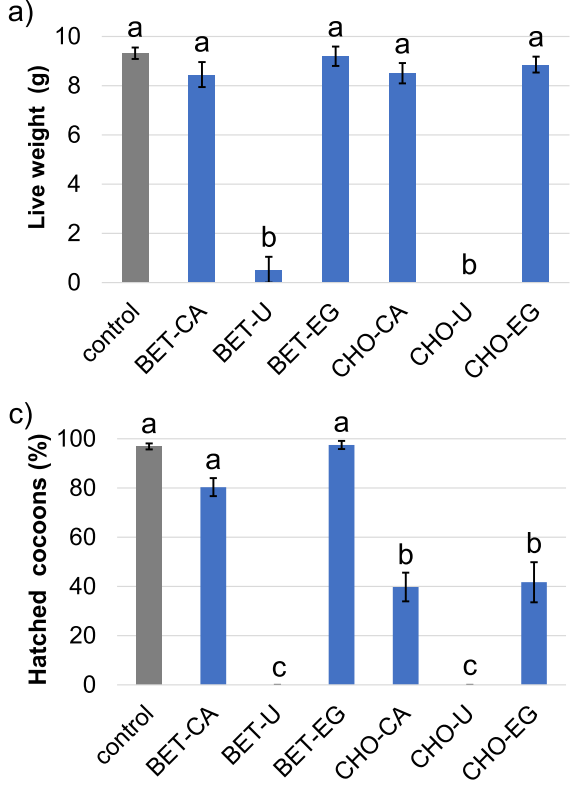

b)

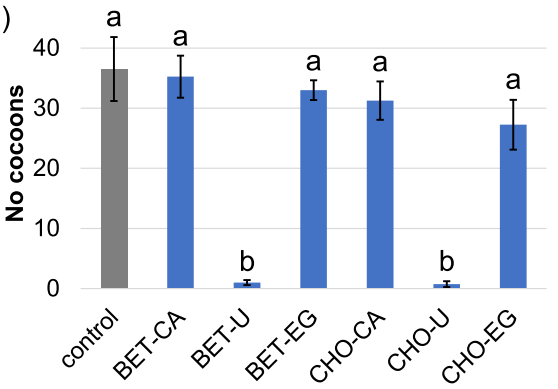

d) 120

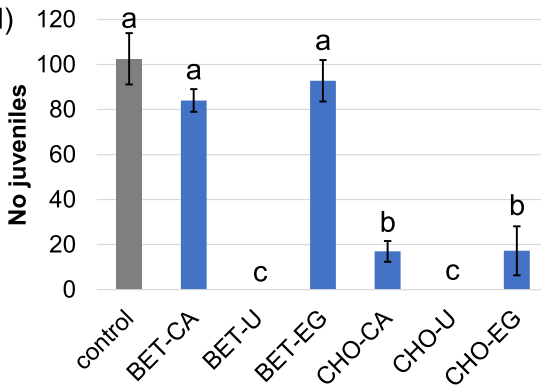

Figure 6. Effect of different DES applied into the soil on survival, growth, and reproduction of the earthworm Eisenia andrei: (a) live weight of adults after 28 days; (b) total number of laid cocoons; (c) percent of hatched cocoons; (d) number of live juveniles at the end of the experiment. Values are reported as mean \pm standard error $(n=4)$. Treatments marked with the same letter are not significantly different from each other.

exposure to the six DES and their polyphenol formulations applied into the soil was evaluated (Figure 4). The same concentration used for the filter paper germination test $(34 \mathrm{mM}$ of HBA) was used, and oat (Avena sativa) was chosen as the test species. Cress (L. sativum) was also tested using the same procedure, to verify if the adverse effect of acidic DES observed in the filter paper germination test also occurred when the exposure was through soil. To the best of our knowledge, this kind of evaluation has never been done before with any DES. Shoot dry weight (Figure $4 a, c$ ), shoot length (Figure $4 b, d$ ), and visible detrimental effects on different parts of the plant (Figure S6, Supporting Information) were evaluated as end points and compared to those of untreated control plants.

All DES and DES-PF formulations based on citric acid (CA) and ethylene glycol (EG) as HBD did not affect oat growth: shoot dry weight and length were not significantly different from the control, and there was no visually observable

difference in root growth (Figure S5, Supporting Information). This confirms their low phytotoxicity, especially at concentrations 1.7 times higher than those effective in inhibiting urease activity. Differently from what happened in the filter paper contact germination test, cress treated with BET-CA (Figure S7, Supporting Information) was not negatively affected by the presence of acidic DES. BET-U and BET- $\mathrm{U}$ -PF exerted an adverse effect on plant growth, both in terms of shoot biomass and length, and the inhibition was more pronounced with the pure DES than with DES-PF formulation (actually, shoot weight for BET-U-PF was not significantly different from the control). This behavior did not occur with $\mathrm{CHO}-\mathrm{U}$ and $\mathrm{CHO}-\mathrm{U}-\mathrm{PF}$ that allowed a shoot growth similar to the control. On the other hand, both urea based DES and their polyphenol formulations caused a visible reduction in root growth (Figure S5, Supporting Information). Since the BET-U combination had a clear adverse effect on both shoot and root growth, a further test was performed to evaluate the contribution of BET and $\mathrm{U}$, each tested at the concentration at which it is present in the DES $(34 \mathrm{mM}$ for $\mathrm{BET}$ and $68 \mathrm{mM}$ for $\mathrm{U}$ ) (Figure 5). The effect of BET and $\mathrm{U}$ on shoot dry weight was not significant, but BET-U caused an evident, statistically significant reduction. A similar pattern was observed for shoot length: even though $U$ alone caused a significant reduction, the effect was significantly stronger when combined with BET. Therefore, the DES was more toxic than its individual components. In particular, BET was not toxic at the tested concentration, but its combination with $\mathrm{U}$ increased the toxicity of the latter. This suggests a possible synergism between HBA and HBD. An opposite trend was reported in 
the literature for $\mathrm{CHO}-\mathrm{U}$ that was less inhibitory than $\mathrm{CHO}$ alone on garlic root growth. ${ }^{28}$

Earthworm Reproduction Test. The effect of soils spiked with BET and $\mathrm{CHO}$ based DES (without polyphenols) on survival, growth, and reproduction of the earthworm Eisenia andreai was assessed by testing the same concentration used for $L$. sativum and A. sativa toxicity tests (Figure 6). Soil $\mathrm{pH}$ was within 7.0 and 7.8 for all treatments during the 56 day exposure, with the exception of the $\mathrm{U}$ based DES, where $\mathrm{pH}$ in the range 8.0-8.5 was measured on days 1 and 14. All tested CHO and BET-DES did not alter the live weight of adults after 28 days, apart from when $U$ was used as the HBD. Both $U$ based DES in fact caused severe mortality of the adult worms since the first days of exposure: on day 7 , about half of the individuals were found dead on the soil surface. At the end of the 28 day exposure, only three worms treated with BET $-\mathrm{U}$, all found in the same container, had survived. On the other hand, no mortality was observed in the control and the other DES treatments after 28 days. Apart from $U$ based DES, where biomass was zeroed or severely reduced due to mortality, wet weights showed no significant differences either on day 28 (Figure 6a).

Effects on reproductive end points are shown in Figure $6 \mathrm{~b}-$

d. The total number of laid cocoons was not significantly different from the control in any DES treatment apart when $U$ was used as HBD. A very low number of cocoons were recovered on day 56 from the containers treated with both $U$ based DES ( $0-2$ cocoons per replicate), as expected due to the high mortality of the parent adults. The percentage of hatched (empty) cocoons (Figure 6c) was severely reduced in the containers treated with $\mathrm{CHO}$ based DES. An even larger reduction in the number and total dry weight of juveniles recovered on day 56 was observed for these treatments (Figure $6 \mathrm{~d}$, Figure S8c, Supporting Information). Recovered juveniles on average were larger in the $\mathrm{CHO}$ treatments $(2.4-2.5 \mathrm{mg}$ ) than in the control and in BET based DES (1.4-2.6 mg) (Figure S8d, Supporting Information). This difference was not significant, due to the variability within treatments. However, it suggests that hatched juveniles were not negatively affected by $\mathrm{CHO}$ based DES and that the lower number allowed a faster growth. In summary, $\mathrm{CHO}$ based DES (even CHO-EG) at the tested HBA concentration (34 $\mathrm{mM})$ severely impaired earthworm reproduction, acting specifically on the ability of the eggs to develop into viable newborns; this finding is in line with some studies reported in the literature that suggest a moderate toxicity of $\mathrm{CHO}$ based DES against various bio logical targets. ${ }^{46}$ However, it is worth mentioning that this was the only one case in which a negative effect of the DES CHO- EG was here observed; further investigations are surely necessary to determine a clear dose-response relationship and if polyphenol incorporation in DES could mitigate the toxic effect. On the other hand, BET based DES, and specifically BET-EG, was nontoxic for not one of the tested endpoints. This could suggest BET-EG and its polyphenol formulation as the best combination in terms of antiurease activity (since it showed the second best urease inhibition, with a reduction of ca. $50 \%$ at 20 mM HBA concentration), antioxidant activity (similar to that of EtOH extract), no phytotoxicity, and no toxicity against earthworms at the tested concentration.

\section{ASSOCIATED CONTENT}

\section{Supporting Information}

The Supporting Information is available free of charge on the ACS Publications website at DOI: 10.1021/acssusche meng.9b03493.

Detailed experimental procedures for the quantification of polyphenols and total sugars in the extracts, determination of the antioxidant activity and phenolic profile of the extracts, toxicity tests against plants and earthworms. Effect of DES (without polyphenols) on urease activity; chromatograms of phenolic compounds extracted by $\mathrm{CHO}-\mathrm{EG}$ and ethanol and main peak classes. Effect of different HBA and HBD on Lepidium sativum germination in a filter paper contact test; effect of BET-CA applied into the soil on early growth of Lepidium sativum; visual effects of DES on Avena sativa roots and shoots; effect of different DES applied into the soil on survival, growth and reproduction of the earthworm Eisenia andrei (PDF)

\section{AUTHOR INFORMATION}

\section{Corresponding Author}

*E mail: chiara.samori3@unibo.it; phone: 00390544937353. ORCID

Chiara Samorì: 0000000254482709

Luca Mazzei: 0000000313359365

Stefano Ciurli: 000000019557 926X

Giancarlo Cravotto: 0000000175747350

Notes

The authors declare no competing financial interest.

\section{ACKNOWLEDGMENTS}

We thank the University of Bologna (RFO program) for funding. L.M. is supported by the University of Bologna and by CIRMMP (Consorzio Interuniversitario di Risonanze Mag netiche di Metallo Proteine).

\section{ABBREVIATIONS}

DES, deep eutectic solvents; $\mathrm{CHO}$, choline chloride; BET, betaine; CA, citric acid; EG, ethylene glycol; U, urea; JBU, jack bean urease; HBA, hydrogen bond acceptor; HBD, hydrogen bond donor; RSL, relative shoot length; RRL, relative root length; DES-PF, deep eutectic solvent-polyphenol formula tions

\section{REFERENCES}

(1) Mobley, H. L.; Hausinger, R. P. Microbial ureases: significance, regulation, and molecular characterization. Microbiol. Rev. 1989, 53, 85-108.

(2) Zambelli, B.; Musiani, F.; Benini, S.; Ciurli, S. Chemistry of $\mathrm{Ni}^{2+}$ in urease: sensing, trafficking, and catalysis. Acc. Chem. Res. 2011, 44, 520-530.

(3) Maroney, M. J.; Ciurli, S. Nonredoxnickel enzymes. Chem. Rev. 2014, 114, 4206-4228.

(4) Mazzei, L.; Musiani, F.; Ciurli, S. Urease, in The Biological Chemistry of Nickel; Zamble, D.; Rowińska Żyrek, M., Kozlowski, H., Eds.; The Royal Society of Chemistry, London, 2017; Vol. 5, pp 6097.

(5) Blakeley, R. L.; Hinds, J. A.; Kunze, H. E.; Webb, E. C.; Zerner, B. Jack bean urease (EC 3.5.1.5). Demonstration of a carbamoyl transfer reaction and inhibition by hydroxamic acids. Biochemistry 1969, 8, 1991-2000. 
(6) Dixon, N. E.; Riddles, P. W.; Gazzola, C.; Blakeley, R. L.; Zerner, B. Jack bean urease (EC 3.5.1.5). On the mechanism of action of urease on urea, formamide, acetamide, $\mathrm{N}$ methylurea, and related compounds. Can. J. Biochem. 1980, 58, 1335-1344.

(7) Krajewska, B. Ureases I. Functional, catalytic and kinetic properties: A review. J. Mol. Catal. B: Enzym. 2009, 59 (1-3), 9-21.

(8) Cameron, K. C.; Di, H. J.; Moir, J. L. Nitrogen losses from the soil/plant system: a review. Ann. Appl. Biol. 2013, 162, 145-173.

(9) Canfield, D. E.; Glazer, A. N.; Falkowski, P. G. The evolution and future of Earth's nitrogen cycle. Science 2010, 330, 192-196.

(10) Bremner, J. M.; Mulvaney, R. L. Urease activity in soils, in Soil enzymes; Burns, R.G., Ed.; Academic Press: New York, 1978; p 149, DOI: $10.1007 / \mathrm{BF} 00018046$.

(11) McCarty, G. W.; Bremner, J. M.; Chai, H. S. Effect of N (n butyl) thiophosphorictriamide on hydrolysis of urea by plant, microbial, and soil urease. Biol. Fertil. Soils 1989, 8, 123-127.

(12) Christianson, C. B.; Byrnes, B. H.; Carmona, G. A comparison of the sulfur and oxygen analogs of phosphoric triamide urease inhibitors in reducing urea hydrolysis and ammonia volatilization. Fert. Res. 1990, 26, 21-27.

(13) Mazzei, L.; Cianci, M.; Contaldo, U.; Musiani, F.; Ciurli, S. Urease inhibi tion in the presence of $\mathrm{N}$ ( $\mathrm{n}$ butyl) thiophosphorictriamide, a suicide substrate: structure and kinetics. Biochemistry 2017, 56, 5391-5404.

(14) Krogmeier, M. J.; McCarty, G. W.; Bremner, J. M. Potential phytotoxicity associated with the use of soil urease inhibitors. Proc. Natl. Acad. Sci. U. S. A. 1989, 86 (4), 1110-1112.

(15) Watson, C. J.; Miller, H. Short term effects of urea amended with the urease inhibitor $\mathrm{N}$ ( $\mathrm{n}$ butyl) thiophosphorictriamide on perennial ryegrass. Plant Soil 1996, 184 (1), 33-45.

(16) Cruchaga, S.; Artola, E.; Lasa, B.; Ariz, I.; Irigoyen, I.; Moran, J. F.; Aparicio Tejo, P. M. Short term physiological implications of NBPT application on the N metabolism of Pisumsativum and Spinaceaoleracea. J. Plant Physiol. 2011, 168 (4), 329-336.

(17) Mazzei, L.; Cianci, M.; Musiani, F.; Lente, G.; Palombo, M.; Ciurli, S. Inactivation of urease by catechol: Kinetics and structure. J. Inorg. Biochem. 2017, 166, 182-189.

(18) Fernando, V.; Roberts, G. R. The partial inhibition of soil urease by naturally occurring polyphenols. Plant Soil 1976, 44 (1),

(19) Mohanty, S.; Patra, A. K.; Chhonkar, P. K. Neem (Azadirachtaindica) seed kernel powder retards urease and nitrification activities in different soils at contrasting moisture and temperature regimes. Bioresour. Technol. 2008, 99, 894-899.

(20) Modolo, L.; de Souza, A. X.; Horta, L. P.; Araujo, D. P.; de Fátima, A. An overview on the potential of natural products as ureases inhibitors: A review. J. Adv. Res. 2015, 6 (1), 35-44.

(21) Ruesgas Ramón, M.; Figueroa Espinoza, M. C.; Durand, E. Application of deep eutectic solvents (DES) for phenolic compounds extraction: overview, challenges, and opportunities. J. Agric. Food Chem. 2017, 65, 3591-3601.

(22) Sut, S.; Faggian, M.; Baldan, V.; Poloniato, G.; Castagliuolo, I.; Grabnar, I.; Perissutti, B.; Brun, P.; Maggi, F.; Voinovich, D.; Peron, G.; Dall'Acqua, S. Natural deep eutectic solvents (NADES) to enhance berberineabsorption: an in vivo pharmacokinetic study. Molecules 2017, 22, 1921.

(23) Radosevic, K.; Curko, N.; Gaurina Srcek, V.; Cvjetko Bubalo, M.; Tomasevic, M.; Kovacevic Ganic, K.; Radojcic Redovnikovic, I. Natural deep eutectic solvents as beneficial extractants forenhance ment of plant extracts bioactivity. LWT Food Sci. Technol. 2016, 73, $45-51$.

(24) Zhao, B. Y.; Xu, P.; Yang, F. X.; Wu, H.; Zong, M. H.; Lou, W. Y. Biocompatible deep eutectic solvents based on choline chloride: characterization and application to the extraction of rutin from Sophora japonica. ACS Sustainable Chem. Eng. 2015, 3, 2746-2755.

(25) Kudłak, B.; Owczarek, K.; Namieśnik, J. Selected issues related to the toxicity of ionic liquids and deep eutectic solvents a review. Environ. Sci. Pollut. Res. 2015, 22, 11975-11992.
(26) Hayyan, M.; Hashim, M. A.; Hayyan, A.; Al Saadi, M. A.; Al Nashef, I. M.; Mirghani, M. E. S.; Saheed, O. K. Are deep eutectic solvents benign or toxic? Chemosphere 2013, 90, 2193-2195.

(27) Blakeley, R. L.; Webb, E. C.; Zerner, B. Jack bean urease (EC 3.5.1.5). A new purification and reliable rate assay. Biochemistry 1969, 8, 1984-1990.

(28) Wen, Q.; Chen, J. X.; Tang, Y. L.; Wang, J.; Yang, Z. Assessing the toxicity and biodegradability of deep eutectic solvents. Chemo sphere 2015, 132, 63-69.

(29) Radosevic, K.; Cvjetko Bubalo, M.; Gaurina Srcek, V.; Grgas, D.; Landeka Dragicevic, T.; Radojcic Redovnikovic, I. Evaluation of toxicity and biodegradability of choline chloride based deep eutectic solvents. Ecotoxicol. Environ. Saf. 2015, 112, 46-53.

(30) UNI 11357: 2010. Water Quality Determination of the inhibition of the seed germination and root elongation of Cucumissativus L. (cucumber), Lepidiumsativum L. (water cress), Sorghum saccharatum Moench (sorghum) Short Chronic Toxicity Test. Ente Nazionale Italiano di Unificazione (UNI).

(31) ISO 11269 2: 2012 Soil quality Determination of the effects of pollutants on soil flora Part 2: Effects of contaminated soil on the emergence and early growth of higher plants.

(32) OECD Guidelines for the Testing of Chemicals, Section 2 Effects on Biotic Systems, Test No. 222: Earthworm Reproduction Test (Eiseniafetida/Eiseniaandrei).

(33) Makris, D. P. Green extraction processes for the efficient recovery of bioactive polyphenols from wine industry solid wastes Recent progress. Cur. Opin. Green Sus. Chem. 2018, 13, 50-55.

(34) CvjetkoBubalo, M.; Curko, N.; Tomašević, M.; KovačevićGanić, K.; RadojčićRedovniković, I. Green extraction of grape skin phenolics by using deep eutectic solvents. Food Chem. 2016, 200, 159-166.

(35) Mouratoglou, E.; Malliou, V.; Makris, D. P. Novel glycerol based natural eutectic mixtures and their efficiency in the ultrasound assisted extraction of antioxidant polyphenols from agri food waste biomass. Waste Biomass Valorization 2016, 7, 1377-1387.

(36) Jeong, K. M.; Zhao, J.; Jin, Y.; Heo, S. R.; Han, S. Y.; Yoo, D. E.; Lee, J. Highly efficient extraction of anthocyanins from grape skin using deep eutectic solvents as green and tunable media. Arch. Pharmacal Res. 2015, 38, 2143-2152.

(37) Duan, L.; Dou, L. L.; Guo, L.; Li, P.; Liu, E. H. Comprehensive evaluation of deep eutectic solvents in extraction of bioactive natural products. ACS Sustainable Chem. Eng. 2016, 4 (4), 2405-2411.

(38) Wan Mahmood, W. M. A.; Lorwirachsutee, A.; Theodoropoulos, C.; Gonzalez Miquel, M. Polyol based deep eutectic solvents for extraction of natural polyphenolic antioxidants from Chlorella vulgaris. ACS Sustainable Chem. Eng. 2019, 7 (5), 50185026.

(39) Bajkacz, S.; Adamek, J. Development of a method based on natural deep eutectic solvents for extraction of flavonoids from food samples. Food Anal. Method. 2018, 11, 1330-1334.

(40) Zeng, Q.; Wang, Y.; Huang, Y.; Ding, X.; Chen, J.; Xu, K. Deep eutectic solvents as novel extraction media for protein partitioning. Analyst 2014, 139, 2565-2573.

(41) Zhang, L.; Wang, M. Optimization of deep eutectic solvent based ultrasound assisted extraction of polysaccharides from Dioscor eaoppositaThunb. Int. J. Biol. Macromol. 2017, 95, 675-681.

(42) Benini, S.; Kosikowska, P.; Cianci, M.; Mazzei, L.; Vara, A. G.; Berlicki, L.; Ciurli, S. The crystal structure of Sporosarcinapasteurii urease in a complex with citrate provides new hints for inhibitor design. JBIC, J. Biol. Inorg. Chem. 2013, 18, 391-399.

(43) Kammerer, D.; Claus, A.; Carle, R.; Schieber, A. Polyphenol screening of pomace from red and white grape varieties (Vitisvinifera L.) by HPLC DAD MS/MS. J. Agric. Food Chem. 2004, 52, 43604367.

(44) Cotoras, M.; Vivanco, H.; Melo, R.; Aguirre, M.; Silva, E.; Mendoza, L. In vitro and in vivo evaluation of the antioxidant and prooxidant activity of phenolic compounds obtained from grape (Vitisvinifera) pomace. Molecules 2014, 19, 21154-21167. 
(45) Halder, A. K.; Cordeiro, M. N. D. S. Probing the environmental toxicity of deep eutectic solvents and their components: an in silico modeling approach. ACS Sustainable Chem. Eng. 2019, 7 (12), 10649-10660.

(46) de Morais, P.; Goncalves, F.; Coutinho, J. A. P.; Ventura, S. P. M. Ecotoxicity of cholinium based deep eutectic solvents. ACS Sustainable Chem. Eng. 2015, 3, 3398-3404. 